\title{
Primary squamous cell carcinoma of endometrium-
} a rare presentation

\begin{abstract}
Primary endometrial squamous cell carcinoma is an extremely rare tumor with unclear pathogenesis. We report a case of 55-year-old postmenopausal woman who presented with abdominal distention and blood-stained vaginal discharge for 9 months. Clinically, chronic pyometra was considered. Total abdominal hysterectomy with a bilateral salpingo-oophorectomy was performed and histopathological examination revealed a diagnosis of primary endometrial invasive squamous cell carcinoma with associated complete squamous cell metaplasia of glandular endometrium and coexisting multifocal squamous cell dysplasia, without involvement of the uterine cervix. The tumoral cells showed to be p16 negative and strongly p53 positive.
\end{abstract}

Keywords: endometrium, histopathology, immunohistochemistry, primary, squamous cell carcinoma

\author{
Special Issue - 2018 \\ Kafil Akhtar,' Binjul Juneja,' Ghazala Mehdi, ${ }^{2}$ \\ Seema Rashid ${ }^{3}$ \\ 'Department of Pathology, Jawaharlal Nehru Medical College, \\ Aligarh Muslim University, India \\ 2Department of Pathology, College of Medicine for Girls, Dubai, \\ UAE \\ ${ }^{3}$ Obstetrics and Gynecology, Jawaharlal Nehru Medical College, \\ India
}

Correspondence: Kafil Akhtar, Department of Pathology, Jawaharlal Nehru Medical College, Aligarh Muslim University, Aligarh (U.P), India, Email drkafilakhtar@gmail.com

Received: May 08, 2017| Published: November 30, 2018

\section{Introduction}

Squamous cell carcinoma develops in the endometrium but is extremely rare. Only 64 cases of primary endometrial squamous cell carcinoma (PESCC) have been documented in the literature. ${ }^{1-3}$ It is usually seen in postmenopausalwomen and is strongly associated with cervical stenosis, pyometra, chronic inflammation, nulliparity and icthyosis uteri. Fluhmannin 1928 devised a strictcriteria for the diagnosis of primary endometrial squamous cell carcinoma, which includes ${ }^{1}$ no coexisting glandular carcinoma in the endometrium, ${ }^{2}$ no connection between the tumor in the endometrium and the squamous epithelium of the cervix, and ${ }^{3}$ no primary squamous cell carcinoma of the cervix. ${ }^{4} \mathrm{We}$ report a case of primary endometrial squamous cell carcinoma in a 55-year-old postmenopausal woman, who presented with abdominal distention and blood-stained vaginal discharge.

\section{Case summary}

A 55-year-old multiparous, postmenopausal woman presented with the history of progressively increasing lower abdominal mass for last 9 months. The patient was diagnosed and treated for $\mathrm{CIN}^{3} 5$ years back, but no foci of invasive carcinoma was identified in the cervix. On recent clinical examination, an abdominal mass of 28 weeks size was palpable in the hypogastric region. Per-speculum examination showed an atrophied cervix. On per-vaginal examination, a midline mass about 28 weeks size was felt. On ultrasonography, uterine cavity was enlarged and distended with fluid and exhibited atrophied cervix. Radiological impression was pyometra or haematometra. Preoperatively, other laboratory tests were within normal limits. Clinically, a diagnosis of pyometra was made.

A total abdominal hysterectomy with a bilateral salpingooophorectomy was performed. Grossly, the uterus was enlarged, $12 \times 10 \times 6 \mathrm{~cm}$ in size and the uterine cavity was markedly distended and filled with purulent material with atrophied cervix (Figure 1).
Microscopic examination of multiple sections of the corpus uteri and cervix revealed total replacement of the entire glandular endometrial lining by squamous epithelium with associated dysplasia and invasive, focally keratinizing, squamous cells carcinoma, deeply invading myometrium (Figure2). Extensive sampling did not reveal normal glandular lining of the endometrial cavity. There was no cervical or serosal involvement by the lesion. Both fallopian tubes, ovaries, omentum and all sampled lymph nodes were negative for malignancy. The diagnosis of primary squamous cell carcinoma of endometrium was made. Immunohistochemistry of the tumoral cells showed p16 negativity (Figure 3 ) and strong nuclear p53 positivity (Figure 4). Adjuvant radiation therapy targeting the parametrial region, along with cisplatinchemosensitization was administered to the patient. She is doing well without any evidence of disease on 12 months of follow up period.

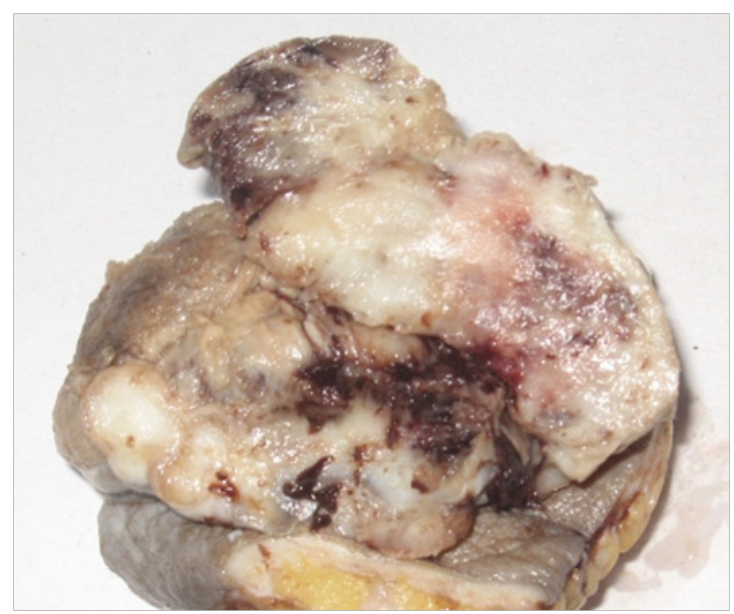

Figure I Grossly, the uterus was enlarged, $12 \times 10 \times 6 \mathrm{~cm}$ in size and the uterine cavity was markedly distended and filled with purulent material with atrophied cervix. 


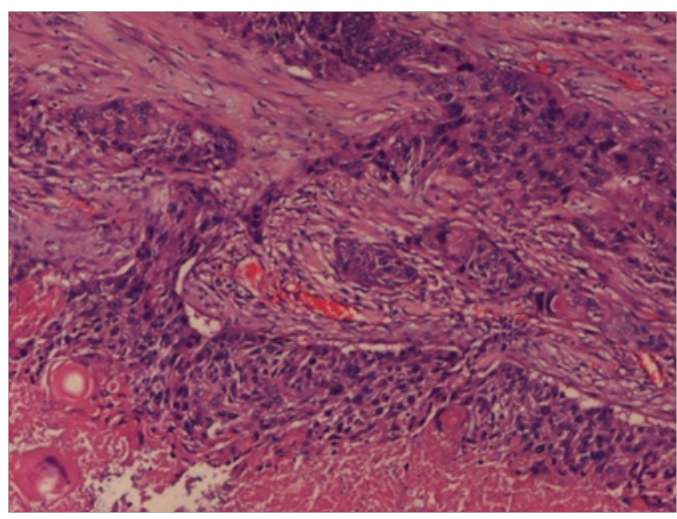

Figure 2 The solid tumor consists of nests of varying size with a squamous differentiation including distinct intercellular bridges and abortive keratinization. Haematoxylin and Eosin $x$ 40X.

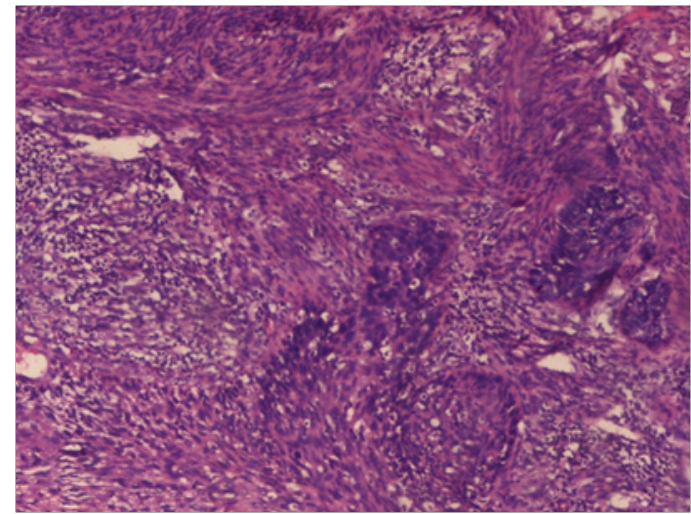

Figure 3 Clusters of squamoid cells with marked cytologicatypia. Haematoxylin and Eosin $x$ 40X.

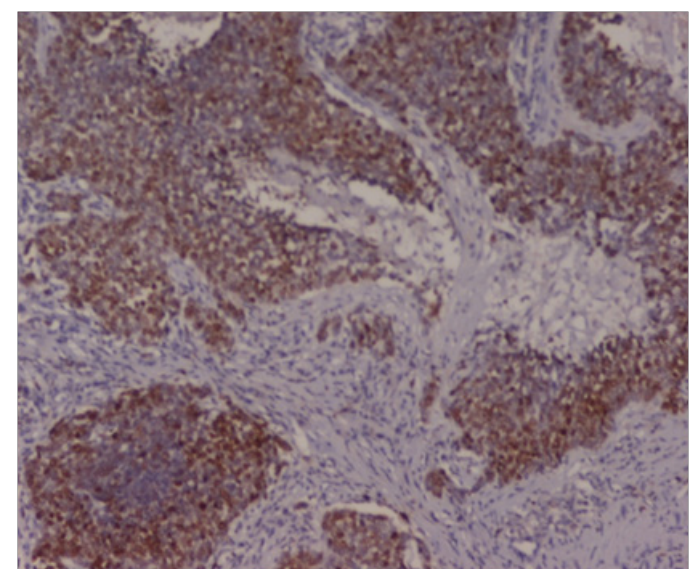

Figure 4 Immunohistochemistry shows strong $p 53$ nuclear positivity of tumor cells. IHC p53 x I0X.

\section{Discussion}

Primary endometrial squamous cell carcinoma is extremely rare, with only 100 cases being reported in the literature, since the first report in 1892 by Gebhard. ${ }^{4,5}$ Endometrial squamous cell carcinoma usually occurs in postmenopausal women, with mean age of presentation being 67 years. ${ }^{3,4}$ Given the rarity of PESCC, the etiology of the disease isunclear. Various authors have speculated that the etiologycould be related to differentiation of pluripotent endometrialprecursor cells, heterotopic cervical tissue, or even HPVinfection..$^{3-5}$ There is a strong association with cervical stenosis, pyometra, chronic inflammation and nulliparity. It is believed that tumor may arise from ichthyosis uteri - a condition in which the endometrium is replaced by keratinized squamous epithelium. ${ }^{5,6}$ The presence of squamous epithelium in the endometrium, variously termed ichthyosis uteri (a condition in which endometrium is replaced by keratinized squamous epithelium), leukoplakia epidermidization, psoriasis uteri, epidermoidheteroplasia, cholesteometra and indirect regenerative squamous metaplasia, has been described under a variety of conditions and is benign in the majority of cases, ${ }^{7,8}$ Invasive squamous cell carcinoma of the endometrium is rare and is thought to arise by one of the two mechanisms: upward spread of a primary cervical lesion or transformation of reserve or stem cells positioned between the glandular basement membrane and the endometrial columnar epithelium. Invasive squamous cell carcinoma as a result of upward spread from the cervix is very unlikely, if the cervical lesion is intramucosal. In the present case, only CIN grade-III was identified in the cervix for which, the patient was already treated. Several studies have explored the immunophenotype and molecular alterations of PESCC. Immunohistochemical and molecular analysis have consistently demonstrated p14 (a growth suppressor gene) andandrogen receptor negativity. ${ }^{9,10}$ Further, four out of ten diagnosed tumors were positive for p16, a tumor suppressor protein, that has been associated with malignancy-inducing human papillomaviruses in the female genital tract., ${ }^{9} 10$ Our patient tested negative for high-risk HPV and $\mathrm{p} 16$ but positive for $\mathrm{p} 53$.

Given the rarity of this condition, there is no consensus for the best way to manage these patients with PESCC. A review of the literature yields sparse reporting of treatment data and associated outcome. No final treatment recommendation has been given so far; therapy usually consists of surgical hysterectomy with adnexectomy and radiotherapy in some cases. ${ }^{11,12}$ In endometrial carcinoma, the presence of a malignant squamous cell component worsens the prognosis. ${ }^{12}$ Although advanced stage disease usually confers a worse prognosis, Horn reports a case of Stage III PESCC with no evidence of disease 15.2 years after diagnosis. ${ }^{13,14}$ The prognosis of squamous cell carcinoma is related to the stage at diagnosis. In a review of reported cases, $80 \%$ of stage I patients survived whereas survival for patients with stage III disease was only $20 \% .{ }^{15,16}$ Although rare, diagnosis of primary squamous cell carcinoma of endometrium should be considered in a postmenopausal elderly female presenting with pyometra and cervical stenosis. ${ }^{917}$ Given the limited numbers of patients, it is not possible to draw conclusions regarding the optimal management. Diagnosis of this rare entity is based on careful pathologic review of the hysterectomy specimen. The underlying etiology or inciting factors leading to this condition, and the optimal treatment thereof, have yet to be determined.

\section{Acknowledgement}

None.

\section{Conflict of interest}

None. 


\section{References}

1. Sarah G, Mehdi KM, John B et al. Primary Squamous Cell Carcinoma of the Endometrium: Two Cases and a Review of the Literature. Diag Cytopathol. 2012;12:231-234.

2. Bifulco G, Giampaolino P, Mandato VD et al. Primary squamous cell carcinoma of the endometrium: a case report. Eur J Gynaecol Oncol. 2011;32(3):350-352.

3. Sah SP, Karki A, Tandon N et al. Squamous cell carcinoma of the endometrium: a case report. Indian J Pathol Microbiol. 2003;46(2):243245 .

4. Fluhmann CF. Squamous epithelium in the endometrium in benign and malignant conditions. Surg GynecolObstet. 1928;46:309-316.

5. Seeger A, Kölbl H, Petry IB et al. p53 is correlated with low BMI negative progesterone receptor status and recurring disease in patients with endometrial cancer. Gynecol Oncol. 2012;125(1):200-207.

6. Yamamoto Y, Izumi K, Otsuka H et al. Primary squamous cell carcinoma of the endometrium: A casereport and a suggestion of new histogenesis. Int J Gynecol Pathol. 2005;14(1):75-80.

7. Chew I, Post MD, Carinelli SG et al. p16 expression in squamous and trophoblastic lesions of the upper female genital tract. Int $J$ Gynecol Pathol. 2010;29:513-522.Horn LC, Richter CE, Einenkel J et al. p16, p14, p53, Cyclin D1 and steroid hormone receptor expressionand human papillomaviruses analysis in primary squamous cell carcinoma of the endometrium. Ann Diagn Pathol. 2006;10:193-196.
8. Yamamoto Y, Izumi K, Otsuka H et al. Primary squamous cell carcinoma of the endometrium: A casereport and a suggestion of new histogenesis. Int J Gynecol Pathol. 2005;14(1):75-80.

9. Giovanna G, Tiziana D, Carla M et al. Primary squamous cell carcinoma of the endometrium: a case report with Immunohistochemical and molecular study. Gynaecol Oncol. 2005;96(3):876-879.

10. Bagga PK, Jaswal TS, Datta U et al. Primary endometrial squamous cell carcinoma with extensive squamous metaplasia and dysplasia. Indian $J$ Pathol Microbiol. 2008;51:267-268.

11. Sung JL, Hyun JC. Primary Endometrial Squamous Cell Carcinoma: A Case Report and Review of Relevant Literature on Korean Women. Korean J Pathol. 2012;46(4):395-398.

12. Creasman WT, Odicino F, Maisonneuve $\mathrm{P}$ et al. Carcinoma of the corpus uteri. FIGO 26th Annual Report on the Results of Treatment in Gynecological Cancer. Int J Gynaecol Obstet. 2006;95(1):105-143.

13. Seo JY, Gu SJ, Park JH et al. A case of primary endometrial squamous cell carcinoma. Korean J Obstet Gynecol. 2001;44:1735-1738.

14. Tong SY, Lee SK, Lee JH et al. Primary squamous cell carcinoma confined to the endometrium of submucosalmyoma. Korean Journal of Obstetrics and Gynecology. 2003;46:1024-1028.

15. Amita K, Padmini J. Squamous Cell Carcinoma of Endometrium with Extensive Icthyosis Uteri. Online J Health Allied Sci. 2010;9(4):25-27.

16. Kim JU, Lee YS, Moon SO et al. A case of primary endometrial squamous cell carcinoma. Korean J Obstet Gynecol. 2003; 46:834-837. 